\title{
Correction to: International capital asset pricing model: the case of asymmetric information and short-sale
}

\author{
Makram Bellalah $^{1,2} \cdot$ Fredj Amine Dammak $^{1}$
}

๑) Springer Science+Business Media, LLC, part of Springer Nature 2019

\section{Correction to: Annals of Operations Research https://doi.org/10.1007/s10479-019-03133-1}

The cited reference Nguyen et al. (2017) should have been set as Al Janabi et al. (2017) in the first paragraph of introduction.

As such, the following corrections should be made in the list of references:

Wrongly Cited Reference:

Nguyen, D., Al Janabi, M. A. M., Hernandez, J. A., \& Berger, T. (2017). Multivariate dependence and portfolio optimization algorithms under illiquid market scenarios. European Journal of Operational Research, 259(3), 1121-1131.

Correct Reference to be Cited:

Al Janabi, M. A. M., Hernandez, J. A., Berger, T., \& Nguyen, D. (2017). Multivariate dependence and portfolio optimization algorithms under illiquid market scenarios. European Journal of Operational Research, 259(3), 1121-1131.

Publisher's Note Springer Nature remains neutral with regard to jurisdictional claims in published maps and institutional affiliations.

The original article can be found online at https://doi.org/10.1007/s10479-019-03133-1.

Makram Bellalah

makram.bellalah@u-picardie.fr

Fredj Amine Dammak

fredjamine@gmail.com

1 CRIISEA Amiens University, Amiens, France

2 CRIISEA, Université de Picardie, Boulevard Saint André, 60000 Beauvais, France 